\title{
The long-lost Myanmar endemic Arundina subsessilis (Orchidaceae) found congeneric with the recently described Chinese Thuniopsis cleistogama
}

\author{
H. Kurzweil ${ }^{1}$, P. Ormerod ${ }^{2} \&$ A. Schuiteman ${ }^{3}$ \\ ${ }^{1}$ Singapore Botanic Gardens, National Parks Board, \\ 1 Cluny Road, 259569 Singapore \\ Hubert_Kurzweil@nparks.gov.sg \\ ${ }^{2}$ P.O. Box 8210, Cairns 4870, Queensland, Australia \\ ${ }^{3}$ Royal Botanic Gardens, Kew, Richmond, Surrey TW9 3AE, U.K.
}

\begin{abstract}
Morphological evidence indicates that the long-lost Arundina subsessilis Rolfe from Upper Myanmar is correctly placed in the genus Thuniopsis L.Li, D.P.Ye \& Shi J.Li. The new combination Thuniopsis subsessilis (Rolfe) Ormerod, Kurzweil \& Schuit. is made. As this is also the only species in Myanmar that had been referred to the genus Dilochia Lindl., this means that Dilochia is not found in Myanmar. In addition, two specimens which were recently reported in central and western Myanmar are also referred to the genus Thuniopsis.
\end{abstract}

Keywords. Myanmar, Orchidaceae, Thunia, Thuniopsis subsessilis

\section{Introduction}

The present paper is part of an ongoing effort to study the rich but as yet poorly known orchid flora of Myanmar. A specimen that was recently collected on Mount Popa in central Myanmar was identified as Thuniopsis cleistogama L.Li, D.P.Ye \& Shi J.Li, which at the time of its publication was considered endemic to Yunnan, China (Li et al., 2015). In addition, a photographic record from the Chin Hills in western Myanmar was referred to this species. These two discoveries were later reported as new distribution records for Myanmar (Kang et al., 2019). It was subsequently pointed out by Paul Ormerod that this orchid is likely the same as the poorly known Dilochia subsessilis (Rolfe) S.Thomas (= Arundina subsessilis Rolfe) from Upper Myanmar, which is suggested by the striking similarities of its protologue and the photos of Thuniopsis cleistogama in Li et al. (2015). We decided to undertake a study of the specimens available, the results of which are presented below.

Arundina subsessilis was described by Rolfe (1914) based on a specimen cultivated by $\mathrm{Mr}$ H.J. Elwes in Gloucestershire that had originally been imported from 'Upper Burma' by Sander \& Sons. No later collections are known to us. On the basis of the flower and bract characters, Rolfe's plant was later transferred to the genus Dilochia Lindl. (Thomas, 1993). A very similar plant was recently described from Yunnan, China, as Thuniopsis cleistogama (Li et al., 2015), but the similarity to Arundina subsessilis was apparently overlooked. 


\section{Materials and methods}

The type specimen of Arundina subsessilis is deposited in the herbarium at Kew and was examined by André Schuiteman; a sketch of floral dissections drawn by Sarah Robbins was also available. Information on the type specimen of Thuniopsis cleistogama was obtained from Li et al. (2015). Two herbarium sheets of the recent collection Cho et al. MM-0507 from central Myanmar, deposited in the herbarium of Hallym University in South Korea, were examined while on loan to the Singapore Herbarium (Hubert Kurzweil). Material was examined with the standard techniques which are usually employed in morphology-based taxonomic studies and sketches were made using a camera lucida. Photographs of the plant from western Myanmar were also studied.

\section{Observations and discussion}

\section{Habit}

All four specimens are slender terrestrial herbs with elongate leafy stems and few-flowered terminal inflorescences (Fig. $1 \& 2$, Table 1). The stems are generally elongate, erect or arching, and are leafy throughout. The length of the stems of the type specimen of Thuniopsis cleistogama is 30-60 cm, while the type specimen of Arundina subsessilis and the collection Cho et al. MM-0507 have shorter stems under $30 \mathrm{~cm}$ long.

\section{Corms}

Prominent underground corms are found in the type specimen of Thuniopsis cleistogama (Li et al., 2015) and in the collection Cho et al. MM-0507 (Fig. 2). These corms consist of several internodes, with roots emerging all over their length. They are considerably larger in the Chinese plant than in the specimen from Myanmar (2-3 cm vs 1.2-1.7 cm). It could not be ascertained whether the type specimen of Arundina subsessilis has corms, as the protologue makes no mention of it and the type specimen lacks a stem base. Information was also not available in the photographic record from western Myanmar.

\section{Leaves}

The number of leaves is greater in the Chinese specimen compared to the Myanmar material (8-14 vs 7-9), probably as a result of the greater stem length. Generally, the leaves are narrowly lanceolate and the size varies only little, ranging from $10-15 \times 1.4-2(-3) \mathrm{cm}$. In all four specimens the leaves are herbaceous or papery in their texture. Arundina subsessilis was transferred to Dilochia on the basis of flower and bract characters (Thomas, 1993). However, 

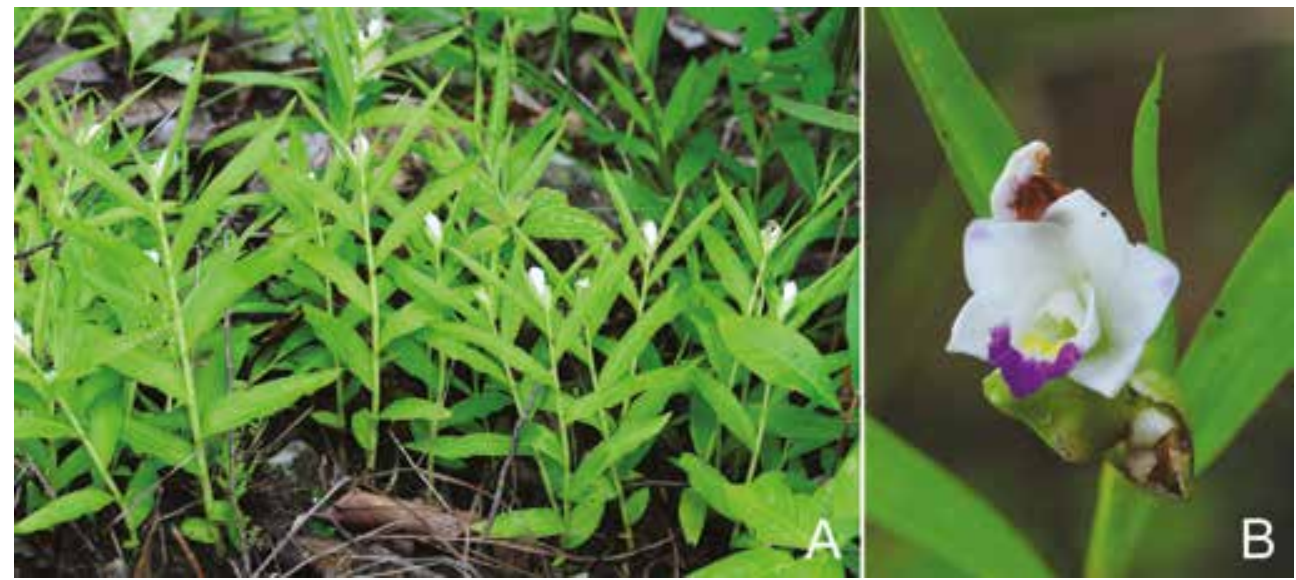

Fig. 1. Thuniopsis cf. subsessilis (Rolfe) Ormerod, Kurzweil \& Schuit. A. Plants. B. Flower. All from Cho et al. MM-0507 on Mount Popa, Myanmar. (Photos: Y.-D. Kim)

it differs in the texture of the leaves which are generally stiff and coriaceous in Dilochia (Pridgeon et al., 2005; Seidenfaden \& Wood, 1992; herbarium sheets at SING; personal observations in the field).

\section{Inflorescences}

Inflorescences are terminal few-flowered racemes. The bracts are persistent and their length varies to some extent. The latter are 14-16 mm long in the type specimen of Thuniopsis cleistogama and 10-21 mm long in the two herbarium collections from Myanmar. They are membranous in the type of Thuniopsis cleistogama and in the collection Cho et al. MM-0507; no information in this regard is available for the type specimen of Arundina subsessilis.

\section{Flowers}

Flowers of the type specimen of Thuniopsis cleistogama mostly only semiopen (only rarely opening widely); also in the collection Cho et al. MM-0507 and apparently also in the type of Arundina subsessilis the flowers do not open very widely. The flowers of the photographic record from western Myanmar are even less open, i.e. they appear somewhat tube-like (illustrated in Kang et al., 2019: Fig. 1B). Only 1-2 of the short-lived flowers are open at a time (no information is available in the type of Arundina subsessilis). The colour of the flowers is nearly identical in all of the specimens, with white or purple-tinged sepals and petals often with purplish tips, a white or purple-tinged lip with pale or dark purple tip and a yellow blotch on the disk and the keels. There is minor variation in the exact colouring of the sepal and petal tips (uniformly white in the type specimen of Thuniopsis cleistogama; with lilac-purple tips in the type 

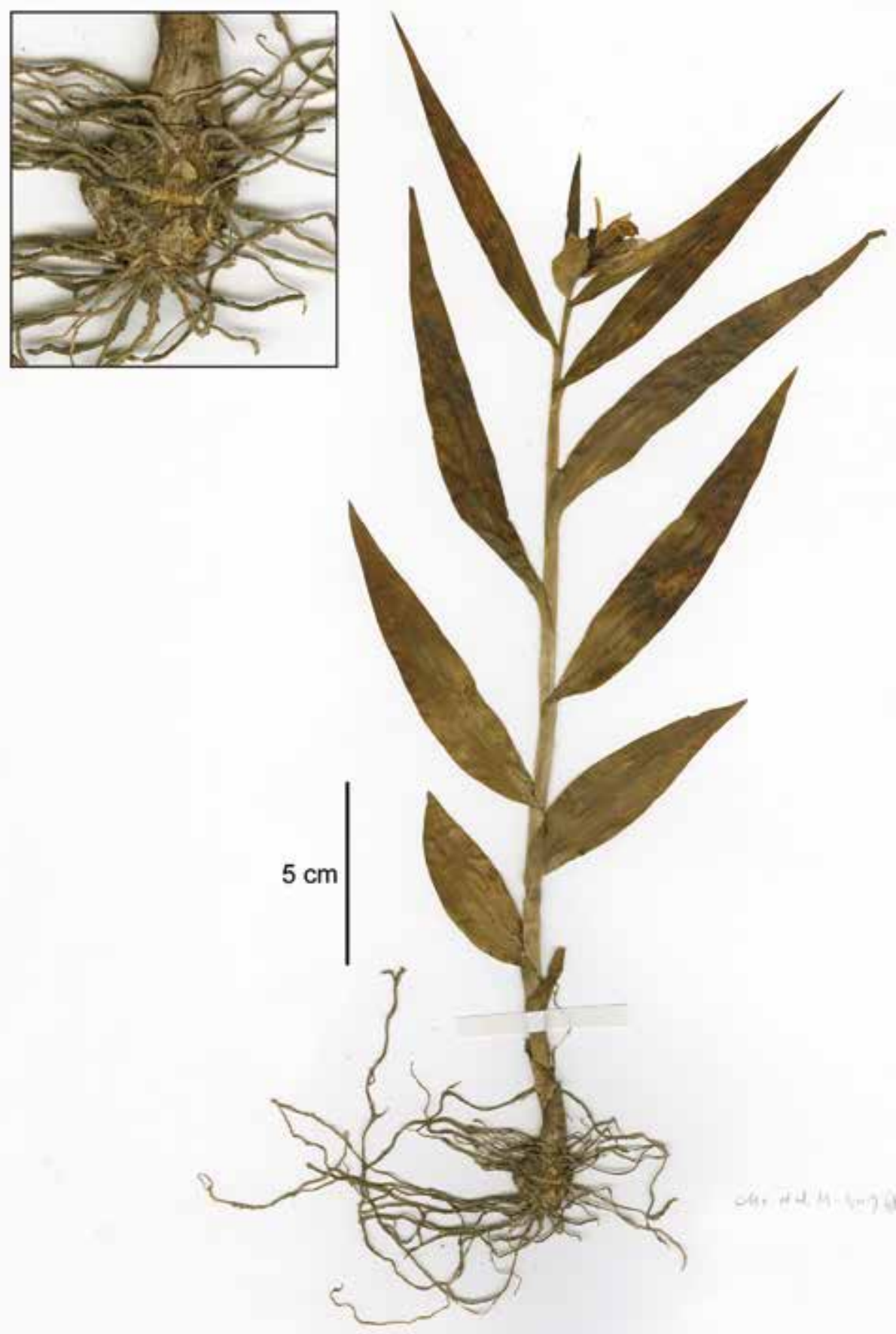

Fig. 2. Thuniopsis cf. subsessilis (Rolfe) Ormerod, Kurzweil \& Schuit. Part of a herbarium specimen of the collection Cho et al. MM-0507 (HHU). The insert shows the corm. (Photos: Bazilah Ibrahim) 







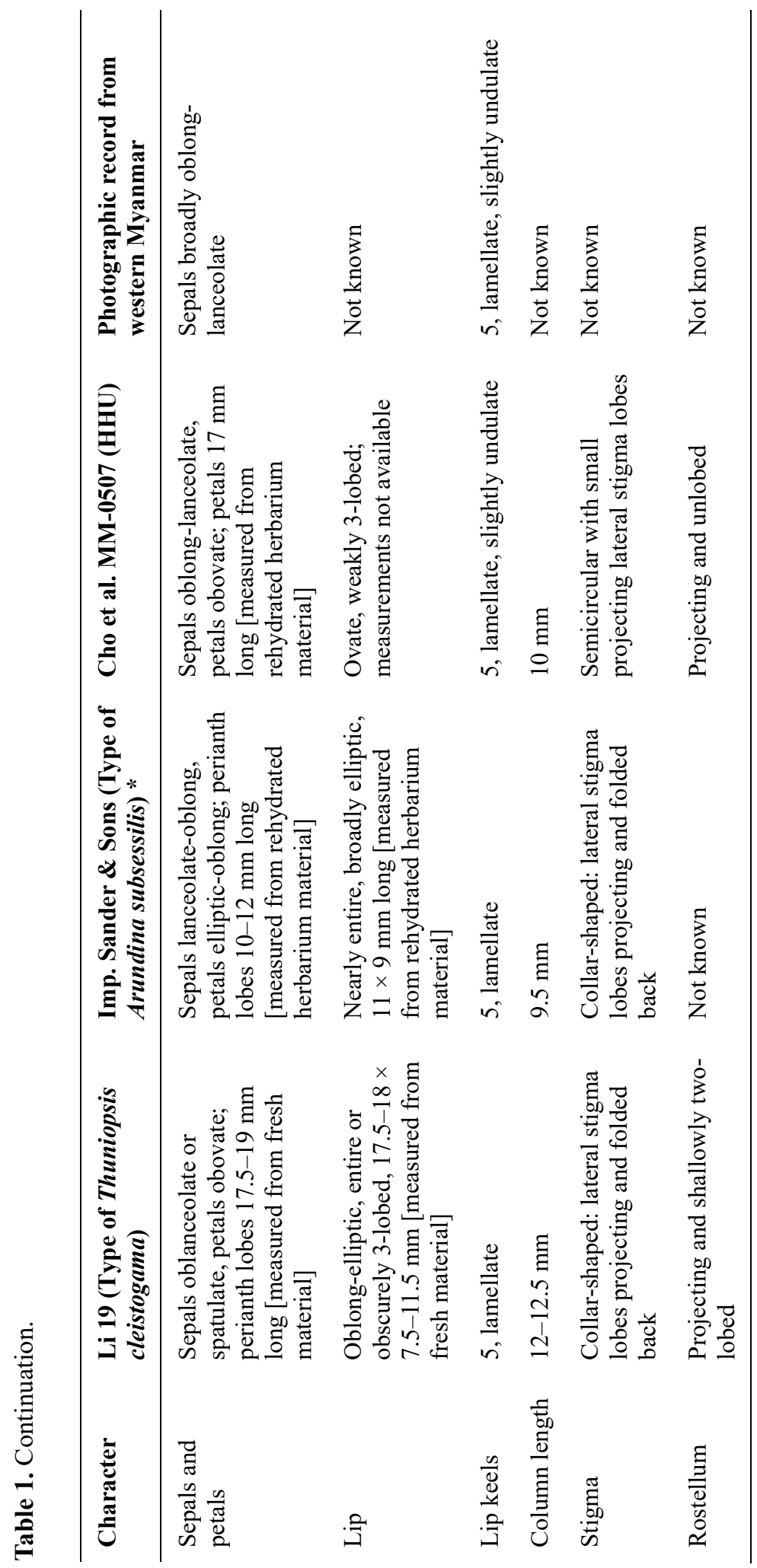


specimen of Arundina subsessilis; with a faint purple blotch near the tip in the collection Cho et al. MM-0507; and petal tips rather prominently purple-tipped in the photographic record from western Myanmar).

In all four specimens the sepals and petals are subequal in length. Accurate information on the size and shape is only available for the type specimens of Thuniopsis cleistogama and Arundina subsessilis. In the collection Cho et al. MM-0507 the flowers are firmly glued onto the sheets and only one petal and one column could be removed and rehydrated. The sepals are oblanceolate, lanceolate-oblong or spathulate, and the petals obovate or elliptic-oblong. Both sepals and petals are glabrous and have acute, subacute or obtuse apices; sepal apices are mucronate in the type specimen of Thuniopsis cleistogama and sometimes in the type specimen of Arundina subsessilis. The length is about 17-19 $\mathrm{mm}$ in the type specimen of Thuniopsis cleistogama [measured from fresh material] and in the collection Cho et al. MM-0507 [measured from rehydrated herbarium material], but is only $10-12 \mathrm{~mm}$ in the type specimen of Arundina subsessilis [measured from rehydrated herbarium material]. However, we do not know whether this latter measurement was taken from a fully open flower or from a flower bud that was just opening up (which would naturally be smaller).

The lip is oblong-elliptic, broadly elliptic or ovate in outline and is entire or obscurely 3-lobed. Here too there is a considerable size difference between the type specimens of Thuniopsis cleistogama and Arundina subsessilis (17.5$18 \mathrm{~mm}$ vs $11 \mathrm{~mm}$ ). In all four examined specimens the lip has five lamellate and sometimes slightly undulate keels.

In all three specimens where herbarium material was examined the column has rather broad apical wings and lacks a column-foot (column features of the photographic record not known). Its length does not show major variation, measuring $9.5-12.5 \mathrm{~mm}$ in all collections. The column is distinctly channelled (concave) on the adaxial side in the type of Arundina subsessilis but is not channelled in the type of Thuniopsis cleistogama (Li et al., 2015) and also does not appear to be channelled in the collection Cho et al. MM-0507. The stigma has lateral projections (likely homologous with the lateral stigma lobes), but their exact extent of formation varies slightly. In the type specimens of Thuniopsis cleistogama and Arundina subsessilis these lateral lobes are very prominent and are folded back so that they are adpressed to the column surface. The resulting stigma was termed 'collar-like' (Li et al., 2015). In the collection Cho et al. MM-0507 these lateral processes of the stigma are very small and are not folded back. The rostellum is a projecting lobe in the type of Thuniopsis cleistogama (Li et al., 2015) and in the collection Cho et al. MM-0507; its front margin is shallowly bilobed in the former collection but obtuse and unlobed in the latter. 


\section{Conclusions}

We agree that the genus Thuniopsis is a valid concept, as demonstrated by the molecular phylogeny in Li et al. (2015), which is also supported by morphology. In Li et al.'s tree it is sister to a clade comprising species of (Bletilla + (Thunia + Dilochia $)$, although the topology of the sister clade has a rather low ML bootstrap value of $62 \%$. More species of Dilochia should be added in future molecular studies to infer a bettersupported topology for these clades.

In the cane-like stem, white flowers, and soft, plicate leaves, Thuniopsis is perhaps most similar to Thunia, in which Thuniopsis cleistogama was at first included (Xu et al., 2010). However, Thunia does not have a subterranean corm and the stem is distinctly fleshy, unlike Thuniopsis. Thunia, moreover, differs in having a spurred lip. In the lack of a spur, Thuniopsis agrees with Bletilla and Dilochia. Bletilla differs in having only few leaves, the sheathing bases of which form a pseudostem, not a true stem, and in having deciduous floral bracts. Although this is nowhere explicitly stated, the stems in Thuniopsis appear to be annual and probably die back completely during the dormant season. Dilochia has coriaceous, non-plicate leaves and multiple, longlived stems that arise from a rhizome, not a corm. Li et al. (2015) mistakenly suggest that Thuniopsis can be distinguished from Dilochia by having "persistent floral bracts that are distinctly longer than the ovary". In Dilochia, the bracts are persistent too and they can sometimes be longer than the pedicellate ovary.

In our study, we were able to show that the four specimens examined share a large number of morphological traits, both vegetative and floral, suggesting that they all belong to the same genus. This necessitates a formal transfer of Arundina subsessilis as there is currently no combination for this species in Thuniopsis.

A number of minor differences among the specimens examined here have been discussed above, but it remains unclear whether these are due to variation in a single species or whether they indicate that more than one taxon is involved. In the absence of any major difference it seems likely that Thuniopsis cleistogama is conspecific with Arundina subsessilis. However, this needs to be assessed in a deeper study when more material is available and the extent of intraspecific variation is better understood.

From the above we conclude that the following new combination for Arundina subsessilis is required:

Thuniopsis subsessilis (Rolfe) Ormerod, Kurzweil \& Schuit., comb. nov. - Arundina subsessilis Rolfe, Bull. Misc. Inform. Kew 1914: 374 (1914). - Dilochia subsessilis (Rolfe) S.Thomas, Kew Bull. 48: 401 (1993). - TYPE: Cultivated specimen grown on from specimen collected in Myanmar, upper part, Sander \& Sons s.n., vouchered on September 1914 as Elwes s.n. (holotype K). (Fig. 3).

? Thunia cleistogama D.P.Ye \& H.Jiang in Xu et al., The Wild Orchids in Yunnan 248, fig. 338a \& 338b (2010), nom. nud. [no specimens cited].

? Thuniopsis cleistogama L.Li, D.P.Ye \& Shi J.Li, PLoS ONE 10(8): 12 (2015). TYPE: China, Yunnan Province, Simao District, 1250 m, 23 June 2012, L. Li 19 (holotype IBSC [not seen]). 

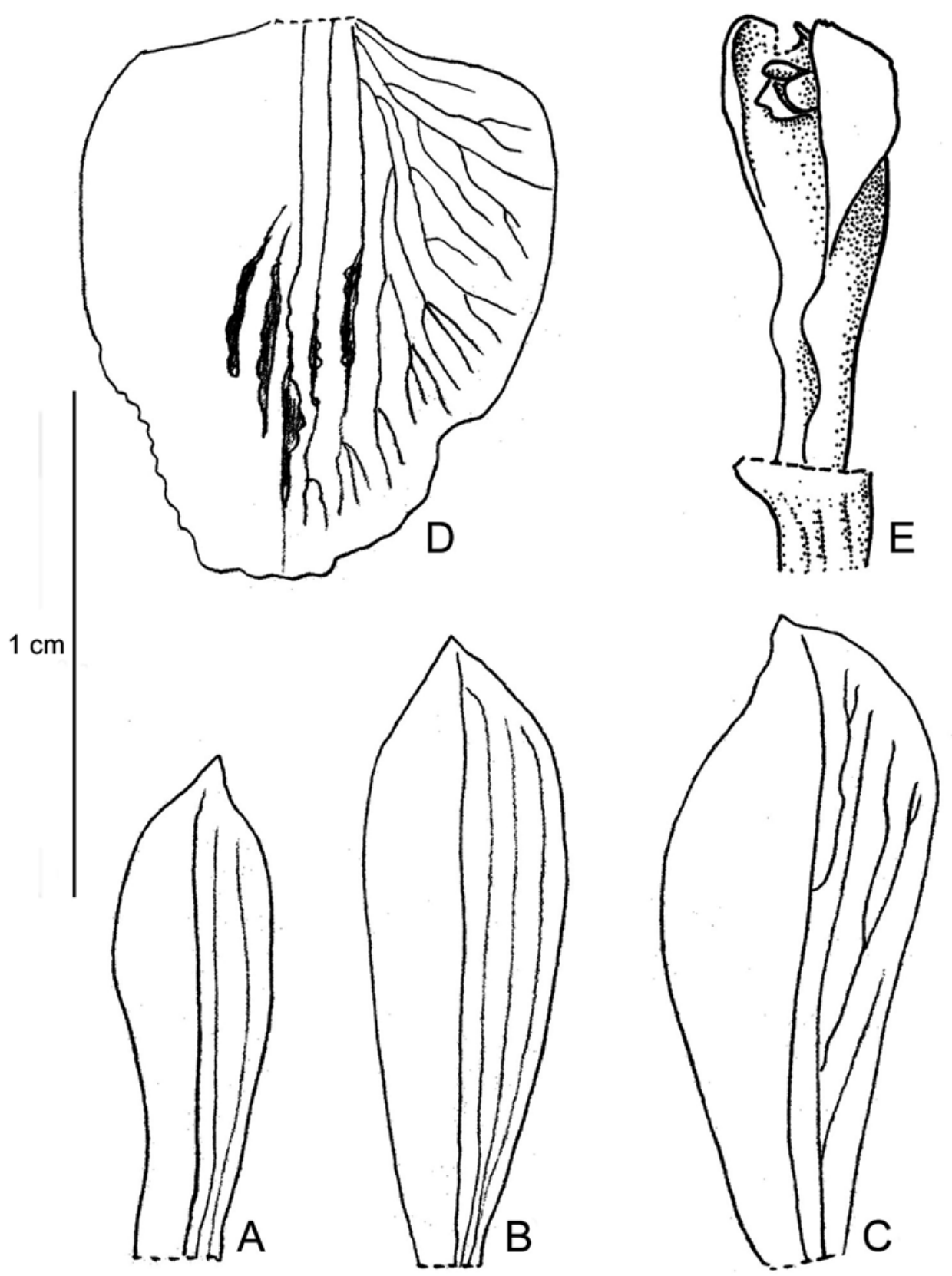

Fig. 3. Thuniopsis subsessilis (Rolfe) Ormerod, Kurzweil \& Schuit. A. Dorsal sepal. B. Lateral sepal. C. Petal. D. Lip. E. Column. A-D from a sketch by Sarah Thomas née Robbins; E drawn by André Schuiteman. All after the holotype. 
Distribution. Upper Myanmar and possibly south-western China (Yunnan), if Thuniopsis cleistogama is conspecific.

Additional specimens examined. MYANMAR: Chin State: Mindat District, Kanpetlet Township, Natma Taung National Park, 495 m, 6 Aug 2016, Kim s.n., photographic record, identification uncertain. Mandalay Region: Myingyan District, Popa Mountain Park, 645 m, 13 Aug 2011, Cho et al. MM-0507 (HHU), identification uncertain, see Fig. 1 \& 2.

Notes. It is surprising that this plant was not rediscovered in Myanmar earlier, given the fact that the two known localities have recently benefitted from extensive collecting work (Popa Mountain Park: N. Tanaka and co-workers [published in Tanaka et al., 2015], Saw Lwin and co-workers; Natma Taung National Park: K. Fujikawa and coworkers, botanists from the Chinese Academy of Sciences). This suggests that the plant is probably quite scarce in these two localities.

As the elongate leafy stem and the foliage resemble those of the genus Thunia Rchb.f., it is likely that non-flowering plants have previously been mistaken for members of that genus. This is even more plausible considering that Thunia and Thuniopsis may grow in the same type of habitat.

\section{Excluded taxa}

Since Dilochia subsessilis has been found to belong in Thuniopsis, the genus Dilochia is currently no longer known from Myanmar.

ACKNOWLEDGEMENTS. The authors would like to thank Prof. Y.D. Kim (Hallym University, S Korea) for permission to reproduce two of his colour photographs and a scan of a herbarium sheet at $\mathrm{HHU}$, and the reviewer Henrik Æ. Pedersen for providing useful comments. Assistance by Serena Lee (making of the photo plates) and Siti Nur Bazilah Binte Mohamed Ibrahim (scanning) is gratefully acknowledged.

\section{References}

Kang, D.H., Cho, S.H., Ong, H.G., Shein Man Ling, Naing Oo Kyaw, Kim, Y.-D. \& Kurzweil, H. (2019). Two new generic records in the orchid flora of Myanmar. Korean J. Pl. Taxon. 49(1): 96-99.

Li, L., Ye, D.-P., Niu, M., Yan, H.-F., Wen, T.-L. \& Li, S.-J. (2015). Thuniopsis: A New Orchid Genus and Phylogeny of the Tribe Arethuseae (Orchidaceae). PLOS ONE 10(8): e0132777.

Pridgeon, A.M., Cribb, P.J., Chase, M.W. \& Rasmussen, F.N. (eds) (2005). Genera Orchidacearum, vol. 4, Epidendroideae, pt. 1. New York: Oxford University Press.

Rolfe, R.A. (1914). New Orchids. Decade 43. Bull. Misc. Inform. Kew 1914: 372-376.

Seidenfaden, G. \& Wood, J.J. (1992). The Orchids of Peninsular Malaysia and Singapore. Fredensborg (Denmark): Olsen \& Olsen. 
Tanaka, N., Yukawa, T., Khin Myo Htwe \& Murata, J. (2015). An Orchid Checklist of Mt. Popa, Central Myanmar. Bull. Natl. Mus. Nat. Sci., Tokyo, B 41(2): 69-89.

Thomas, S. (1993). A New Combination in Dilochia (Orchidaceae). Kew Bull. 48: 401-402.

Xu, Z.-H., Hong, J., Ye, D.-P. \& Liu, E. (2010). The Wild Orchids in Yunnan. Kunming: Yunnan Science \& Technology Press. 
